\title{
Activation of myeloid dendritic cells, effector cells and regulatory T cells in lichen planus
}

\author{
Rosana Domingues ${ }^{1}$, Gabriel Costa de Carvalho ${ }^{1}$, Valéria Aoki ${ }^{2}$, Alberto José da Silva Duarte ${ }^{1}$ \\ and Maria Notomi Sato ${ }^{1 *}$
}

\begin{abstract}
Background: Lichen planus (LP) is a chronic mucocutaneous inflammatory disease. Evaluating the balance between regulatory $T$ cells and effector $T$ cells could be useful for monitoring the proinflammatory profile of $L P$. Therefore, this study aimed to assess populations of dendritic cells (DCs) and regulatory and effector T cells in peripheral blood samples collected from patients with LP to evaluate the polyfunctionality of T cells upon toll-like receptor (TLR) activation.

Methods: Peripheral blood mononuclear cells collected from 18 patients with LP and 22 healthy control subjects were stimulated with agonists of TLR4, TLR7, TLR7/TLR8 or TLR9. Frequencies of circulating IFN- $a^{+}$plasmacytoid DCs (pDCs); TNF- $\mathrm{a}^{+}$myeloid DCs (mDCs); regulatory T cells (Tregs); and IL-17-, IL-10-, IL-22-, TNF-, and IFN- $\gamma-$ secreting T cells were assessed via flow cytometry.

Results: The frequencies of regulatory $\mathrm{CD} 4^{+}$and $\mathrm{CD} 8^{+} \mathrm{CD} 25^{+} \mathrm{Foxp}^{+} \mathrm{CD} 127^{\text {low } /-} \mathrm{T}$ cells and TNF- $\mathrm{a}^{+} \mathrm{mDC}$ s were induced following activation with TLR4, TLR7 and TLR8 agonists in the LP group. Moreover, increased baseline frequencies of $\mathrm{CD} 4^{+} \mathrm{IL}-10^{+} \mathrm{T}$ cells and $\mathrm{CD} 8^{+} \mathrm{IL}-22^{+}$or IFN- $\gamma^{+} \mathrm{T}$ cells were found. In the LP group, TLR4 activation induced an increased frequency of $C D 4^{+} I F N-\gamma^{+} T$ cells, while TLR7/8 and staphylococcal enterotoxin B (SEB) activation induced an increased frequency of $\mathrm{CD}^{+} \mathrm{IL}-22^{+} \mathrm{T}$ cells. An increased frequency of polyfunctional $\mathrm{CD} 4^{+} \mathrm{T}$ cells that simultaneously secreted 3 of the evaluated cytokines (not including IL-10) was verified upon TLR7/8/9 activation, while polyfunctional $\mathrm{CD} 8^{+} \mathrm{T}$ cells were already detectable at baseline.
\end{abstract}

Conclusions: TLR-mediated activation of the innate immune response induced the production of proinflammatory $\mathrm{mDC}$, Tregs and polyfunctional T cells in patients with LP. Therefore, TLR activation has an adjuvant role in inducing both innate and adaptive immune responses.

Keywords: Lichen planus, Toll-like receptor, Dendritic cells, Regulatory T cells, Polyfunctional T cells

\section{Background}

Lichen planus (LP) is a chronic inflammatory disease that affects skin and mucous membranes and can be mediated by $\mathrm{T}$ cells. Although the aetiology is unknown, LP has been associated with human hepatitis $C$ [1] and human herpes virus type 7 infections [2].

\footnotetext{
*Correspondence: marisato@usp.br

${ }^{1}$ Laboratory of Dermatology and Immunodeficiencies, LIM-56, Department of Dermatology, Medical School, University of São Paulo, Institut of Tropical Medicine of São Paulo, Av. Dr. Enéas de Carvalho Aguiar, 500, 3rd floor 24, São Paulo 05403-000, Brazil

Full list of author information is available at the end of the article
}

Previously, we verified that patients with LP exhibit dysfunctional cytokine secretion by peripheral blood mononuclear cells (PBMCs) after Toll-like receptor (TLR) activation. This phenotype was mainly related to the activation of intracellular TLRs, including Poly-RIG/ TLR3, imiquimod/TLR7, CL097/TLR7/8, and CpG/ TLR9; similar events occur during viral infection [3]. Moreover, we showed that up-regulated expression of factors related to the type I IFN axis and antiviral restriction factors as well as enhanced expression of human endogenous retroviruses are characteristic of skin lesions 
in patients with cutaneous LP, attributing a viral aetiology to LP pathogenesis [4].

Plasmacytoid dendritic cells (pDCs) are present in large numbers in LP skin lesions and have the ability to produce large amounts of IFN- $\alpha$ in response to TLR7 and TLR9 stimulation, showing their key role in antiviral responses [2]. In contrast, myeloid dendritic cells (mDCs) with immunoregulatory characteristics are also found in LP lesions [5]. Understanding the cytokine secretion profiles of $\mathrm{pDCs}$ and $\mathrm{mDCs}$ in peripheral blood could provide insights into how dendritic cells (DCs) impact $\mathrm{T}$ cell functions and the balance that exists between regulatory and effector responses in LP.

Regulatory T cells (Tregs) play a crucial role in immune tolerance and the prevention of autoimmune and inflammatory diseases [6, 7]. Tregs express the transcription factor Foxp3 and are classified according to their origin as either thymus-derived Tregs (tTreg), which recognize self antigens, or peripherally derived Tregs (pTreg), which recognize antigens from microbiota and allergens as well as alloantigens [8]. In oral and cutaneous LP lesions, Foxp $^{+} \mathrm{T}$ cells infiltrate both the epidermis and dermis. Moreover, these cells are also found at an increased frequency in the peripheral blood of patients with oral LP (OLP) $[9,10]$. In cutaneous LP, the presence of these cells in peripheral blood has not been evaluated to date.

Increased frequencies of $\mathrm{CD} 4^{+} \mathrm{IFN}-\gamma^{+} \mathrm{T}$ cells and $\mathrm{CD} 4^{+} \mathrm{IFN} \gamma^{+} \mathrm{IL}-17^{+} \mathrm{T}$ cells have been found in the peripheral blood of patients with OLP after stimulation with phorbol myristate acetate (PMA) and ionomycin [11]. Furthermore, $\mathrm{CD} 8^{+} \mathrm{T}$ cells play an important role in LP skin lesions by destroying keratinocytes via the induction of apoptosis through FasL expression, the activation of granzymes and perforin, and the secretion of TNF- $\alpha$ [12]. A link between human papillomavirus virus infection and OLP pathogenesis has been described, including the identification of a massive clonal expansion of $\mathrm{CD}^{+} \mathrm{T}$ cells with an increased frequency of HPV-16-specific CD8 ${ }^{+} \mathrm{T}$ cell subpopulations in patients with OLP [13]. However, in LP, it is unknown whether TLR-mediated activation of cells in peripheral blood may contribute to the adaptive responses of $\mathrm{CD}^{+}$or $\mathrm{CD}^{+} \mathrm{T}$ cells, which are mainly related to the secretion of IL-17 (Th17/Tc17 cells), IL-22 (Th22/Tc22 cells) and IFN- $\gamma$ (Th1/Tc1 cells).

To date, the generation of polyfunctional responses in skin diseases has only been studied in psoriasis and atopic dermatitis [14-16]. Polyfunctionality is defined as the ability to simultaneously produce multiple cytokines and has an important role in viral control. In HIV and tuberculosis, polyfunctionality has been associated with better vaccine response and slower progression to disease. Furthermore, polyfunctional cells are targeted when designing vaccines and immunotherapies that are mediated though cellular responses [17-19].

In this work, we demonstrated that patients with LP have increased frequencies of TNF- $\alpha^{+}$mDCs and $\mathrm{CD} 4^{+} /$ $\mathrm{CD}^{+}$Tregs in their peripheral blood. We also verified that TLR activation led to impaired IL-10 production by $\mathrm{CD} 4^{+} \mathrm{T}$ cells and the presence of Th22/Tc22 cells in peripheral blood. TLR-mediated signalling events induce DC maturation and are crucial to inducing monofunctional or polyfunctional responses by $\mathrm{CD} 4^{+}$and $\mathrm{CD} 8^{+} \mathrm{T}$ cells in patients with LP. Therefore, TLR activation could be useful for the immunomodulation of LP.

\section{Methods}

\section{Study population}

The current study enrolled patients with cutaneous LP ( $n=18$; 3 males, 15 females) from the Dermatological Outpatient Clinic of the Hospital das Clínicas de São Paulo (HC-FMUSP) as well as healthy individuals as controls ( $\mathrm{n}=22 ; 5$ males, 17 females). The majority cohort of patients with LP had the cutaneous form of LP and association with oral form was observed in 3 patients. Patients with other forms of LP, such as lichen planopilaris or drug-induced LP, as well as patients with LP associated with autoimmune diseases and other skin diseases were not included. The majority of the patients had at least two affected limbs, with papules involving up to $30 \%$ of the trunk. None of the patients took any type of topical or systemic corticosteroids, retinoids or immunosuppressants for 1 month prior to blood collection. A serological screening for hepatitis $C$ was performed. The median age was $43.9 \pm 13.5$ years (range: $22-65$ years) for the patients with LP and $40.5 \pm 14.3$ years (range: 20-71 years) for the healthy individuals. All the subjects provided written informed consent under the approval of the São Paulo University Institutional Use Committee (CAPPesq no. 0709/11).

\section{Flow cytometry for Treg analysis}

To analyse Treg populations, PBMCs were isolated from heparinized venous blood by Ficoll-Hypaque gradient centrifugation (GE Healthcare Bio-Sciences AB, Uppsala, Sweden) and diluted in RPMI medium supplemented with $10 \%$ AB human serum (Sigma, St. Louis, MO, USA). The PBMCs were incubated with antibodies against the following proteins at $4{ }^{\circ} \mathrm{C}$ for $30 \mathrm{~min}$ : CD3 (S4.1, Qdot, Invitrogen, Carlsbad, CA, USA), CD4 (RPA T4, Horizon V500), CD8 (RPA T8, Alexa Fluor 700), CD45RA (HI 100, APC-H7), CCR7 (3D12, Alexa Fluor 647), and CD127 (HIL-7R-M21, RPE-Cy7). All antibodies were from BD Biosciences (San Jose, CA, USA). The cells were then fixed, permeabilized and incubated with an antiFoxp3 antibody (PCH101, e-Bioscience, San Diego, CA, 
USA) at $4{ }^{\circ} \mathrm{C}$ for $30 \mathrm{~min}$. The Tregs were characterized as $\mathrm{CD} 3^{+} \mathrm{CD} 4^{+} \mathrm{CD} 25^{+} \mathrm{CD} 127^{\text {low } /-} \mathrm{Foxp} 3^{+}$or $\mathrm{CD} 8^{+} \mathrm{CD} 25^{+}$ CD127 ${ }^{\text {low/- }}$ Foxp $3^{+}$and as thymus-derived Tregs (tTregs; CD45RA ${ }^{+}$Foxp $^{\text {low }}$ ) or peripherally derived Tregs (pTregs; CD45RA ${ }^{-}$Foxp $3^{\text {high }}$ ). A total of 400,000 events were acquired using a flow cytometer (LSR Fortessa, BD Biosciences, USA) with FACS-Diva software (BD Bioscience). The data were analysed using FlowJo software, version 9.4.11 (Tree Star, Inc., Ashland, OR, USA).

\section{Evaluation of DCs and effector T cells}

Cultures of PBMCs $\left(2.0 \times 10^{6}\right.$ cells $\left./ 500 \mu \mathrm{L}\right)$ were incubated in 48-well plates (Costar, Cambridge, MA, USA) in RPMI 1640 medium with ligands for TLR4 (lipopolysaccharide, $2 \mu \mathrm{g} / \mathrm{mL}$ ), TLR7 (imiquimod, $2.5 \mu \mathrm{g} / \mathrm{mL}$ ), TLR7/ TLR8 (CL097, $5 \mu \mathrm{g} / \mathrm{mL}$ ), or TLR9 (oligodeoxynucleotide CpG, $4 \mu \mathrm{M} / \mathrm{mL}$ ) for $16 \mathrm{~h}$ or SEB (enterotoxin B of Staphylococcus aureus, $1 \mu \mathrm{g} / \mathrm{mL}$ ) as a positive control for $6 \mathrm{~h}$ at $37{ }^{\circ} \mathrm{C}$ under $5 \% \mathrm{CO}_{2}$. The stimulus concentrations and culture times were previously determined using a doseresponse curve (Cardoso EC, 2013). All the ligands were obtained from Invivogen (San Diego, CA, USA). Brefel$\operatorname{din} \mathrm{A}(10 \mu \mathrm{g} / \mathrm{mL}$, Sigma $)$ was added to the cells $4 \mathrm{~h}$ after the beginning of the culture. $\mathrm{mDCs}$ were characterized as $\mathrm{Lin}^{-} \mathrm{CD} 11 \mathrm{c}^{+} \mathrm{HLA}-\mathrm{DR}{ }^{+}$, and $\mathrm{pDCs}$ were characterized as $\mathrm{Lin}^{-} \mathrm{CD} 123^{+} \mathrm{HLA}-\mathrm{DR}{ }^{+}$. After the Brefeldin A incubation, the cells were washed and incubated with human IgG for 10 min followed by staining with LIVE/DEAD (Invitrogen), fixation with Cytofix/Cytoperm solution (BD Biosciences) for $20 \mathrm{~min}$ and a wash in Perm/Wash solution. The cells were stained with antibodies against the following proteins: Lineage 1 cocktail (SK-7, Lin1, a mix of CD3, CD14, CD16, CD19, CD20 and CD56) (FITC), HLA-DR (G46-6, Horizon V500), CD123 (7G3, PERCP Cy5.5), CD11c (B-ly6, Alexa fluor 700), IFN- $\alpha$ (7N4-1, Horizon V500) and TNF- $\alpha$ (6401.111, PE). For monofunctional and polyfunctional $\mathrm{T}$ cell analyses, PBMCs were stained with LIVE/DEAD (Invitrogen, viability marker), fixed and permeabilized with Cytofix/Cytoperm solution (BD Biosciences) and then stained with antibodies against CD3 (SP34-2, BV605), CD4 (RPA-34, Horizon V500), CD8 (RPA-T8, PERCP Cy5.5), TNF (MAb11, PECy7), IL-10 (JES3-19F1, APC), CD38 (HIT2, Alexa Fluor 700) and IFN- $\gamma$ (B27, Horizon V450) from BD Biosciences and antibodies against IL-22 (22URTI, PE) and IL-17 (N49-653, Alexa Fluor 488) from eBioscience. A total of 500,000 events were acquired with a flow cytometer (LSRFortessa, BD) and analysed with FlowJo software. The fluorescence minus one (FMO) protocol was used for all analyses to determine the gates. Boolean gate arrays were then created using FlowJo software. This analysis determined the frequency of each cytokine based upon all possible combinations of cytokines. To analyse the polychromatic flow cytometry data and to generate graphical representations of the T cells, the SPICE Program was used (Version 2.9, Vaccine Research Center, NIAID, NIH).

\section{Statistical analysis}

The Mann-Whitney U test was used to compare variables between the patients with LP and the healthy controls. $\mathrm{P} \leq 0.05$ was considered significant.

\section{Results}

\section{$\mathrm{mDCs}$ are responsive to TLR activation in LP}

Previously, we verified that mononuclear cells from patients with LP have altered cytokine secretion upon activation of TLRs with synthetic ligands. This finding mainly applies to intracellular TLR7/TLR8 and TLR9 signalling [3]. One cytokine that is abundantly produced in PBMCs upon TLR activation is TNF [3]. Based on these studies, we analysed the frequency of TNF- $\alpha^{+}$ $\mathrm{mDCs}$ within populations of PBMCs [20]. To evaluate the responsiveness of DCs ( $\mathrm{mDCs}$ and $\mathrm{pDCs}$ ), populations of PBMCs were assessed using flow cytometry to determine the frequencies of TNF- $\alpha^{+}$mDCs and IFN- $\alpha^{+}$pDCs after stimulation with ligands for TLR4 (LPS), TLR7 (imiquimod) and TLR7/8 (CL097), and TLR9 (CPG) or with SEB as a positive control. The gating strategy used to evaluate the pDCs and $\mathrm{mDCs}$ is depicted in Additional file 1: Figure S1.

As shown in Fig. 1, an increased frequency of CD11 ${ }^{+}$HLA-DR ${ }^{+}$TNF- $\alpha^{+}$mDCs was found in the LP samples after stimulation with LPS/TLR4 and CL097/ TLR7-TLR8. No difference was observed following TLR7 activation, indicating that activation of TLR8 using the CL097 compound in mDCs potently induced TNF- $\alpha$ secretion. To induce type I interferon secretion by $\mathrm{CD} 123^{+} \mathrm{HLA}^{-\mathrm{DR}}{ }^{+} \mathrm{pDCs}$, we used TLR7 and TLR9 agonists, which resulted in similar frequencies of IFN- $\alpha^{+}$ pDCs in the LP and HC groups (Fig. 1b).

\section{Patients with LP have an increased frequency of Tregs in peripheral blood}

To verify that $\mathrm{T}$ cells were present in the patients with LP, we evaluated populations of tTregs and pTregs, derived from thymic or peripheral $\mathrm{T}$ cells, respectively [8]. To accomplish this goal, we evaluated the frequencies of $\mathrm{CD}^{+}$and $\mathrm{CD} 8^{+}{ }^{-}$oxp $3^{+}$Tregs in peripheral blood samples collected from the LP and HC groups. The gating strategy used to identify Tregs is shown in Additional file 2: Figure S2.

The patients with LP exhibited increased frequencies of CD $4^{+}$CD $25^{+}$Foxp $3^{+}$CD $127^{\text {low/- }} \mathrm{T}$ cells and $\mathrm{CD} 8^{+}$Tregs (Fig. 2a). Among the different subtypes of Tregs analysed, we verified that similar frequencies of $\mathrm{CD}^{+}$and $\mathrm{CD} 8^{+}$ 


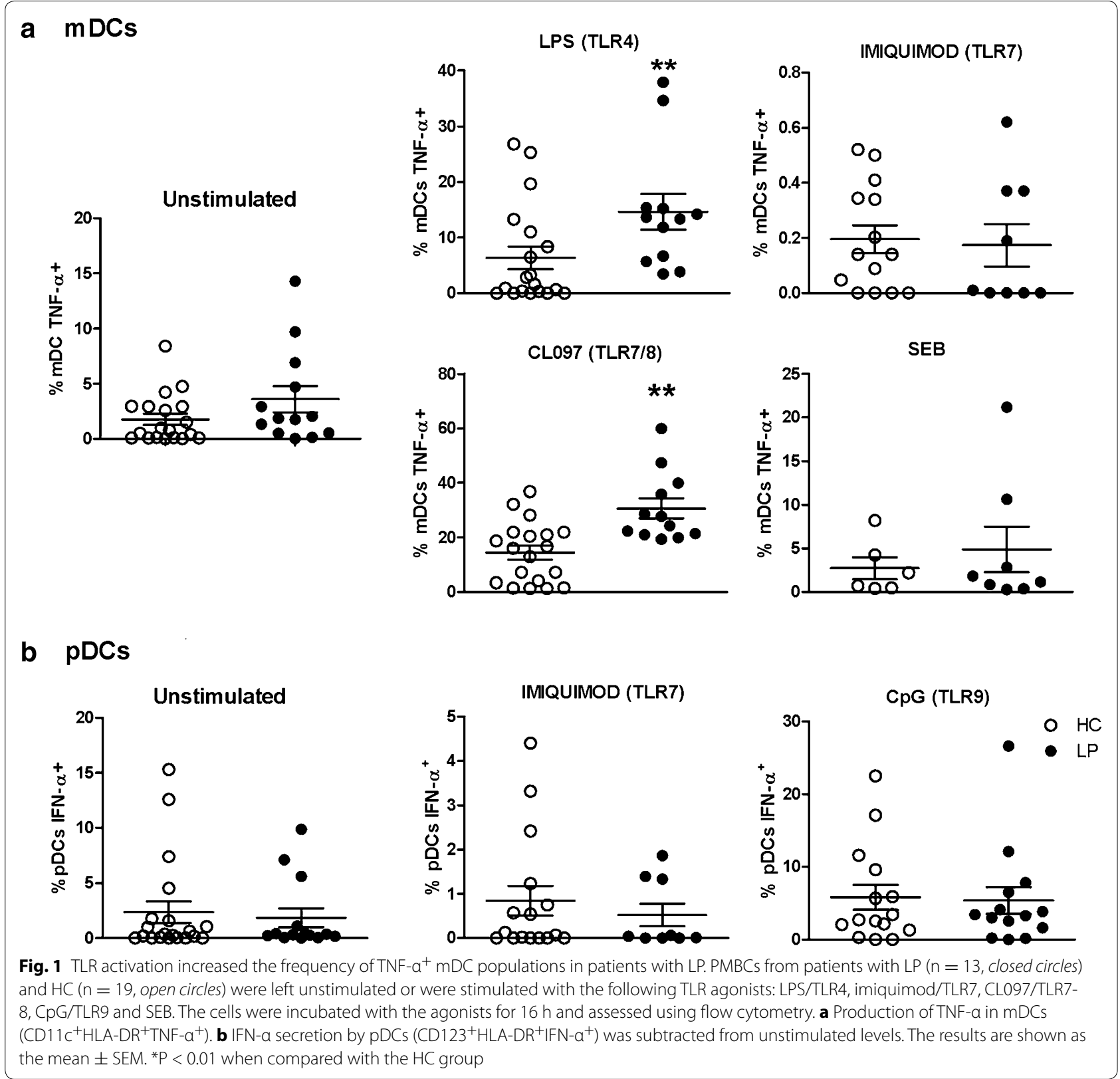

tTregs were present in both groups (Fig. 2b), while the patients with LP had a higher frequency of $\mathrm{CD} 4^{+}$pTregs than the healthy controls (Fig. 2c).

\section{Altered cytokine responses in $\mathrm{CD}^{+}$and $\mathrm{CD}^{+} \mathrm{T}$ cells were induced by TLR activation in patients with LP}

Previously, we verified that TLR activation produces an adjuvant effect by inducing cytokine production in PBMCs [3]. In the current study, we evaluated how stimulation of the innate immune system through TLR activation in T cells influences LP. Additionally, we stimulated PBMCs with TLR agonists such as LPS/TLR4, CL097/
TLR7-8, CpG/TLR9 and SEB and then assessed intracellular levels of IFN- $\gamma$, IL-10, IL-22 and TNF in CD4 ${ }^{+}$ and $\mathrm{CD}^{+} \mathrm{T}$ cells. The gating strategy used to quantify cytokines secreted from $\mathrm{T}$ cells is depicted in Additional file 3: Figure S3 (a, b).

We assessed the frequencies of $\mathrm{CD}^{+} \mathrm{T}$ cells that secreted IFN- $\gamma$ and IL-10 (Fig. 3) and $\mathrm{CD}^{+}{ }^{+} \mathrm{T}$ cells that secreted IFN- $\gamma$, IL-22 and TNF (Additional file 4: Figure S4) because these cytokines are specifically modified after TLR activation. Relative to the $\mathrm{HC}$ group, in the patients with $\mathrm{LP}, \mathrm{CD} 4^{+} \mathrm{IFN}-\gamma^{+} \mathrm{T}$ cell frequency increased after stimulation with a TLR4 agonist and decreased after 

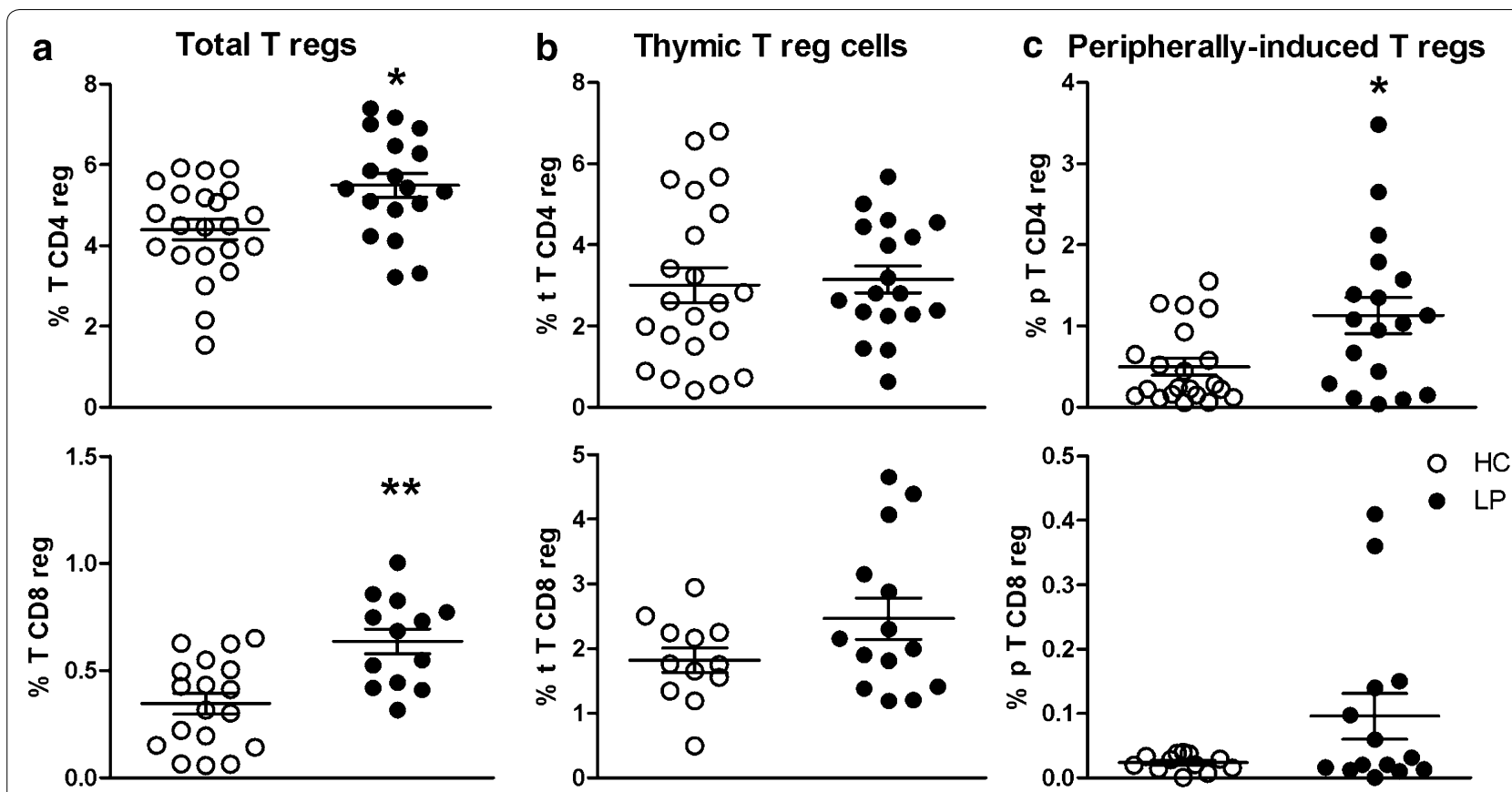

Fig. 2 The frequencies of $\mathrm{CD} 4^{+}$and $\mathrm{CD} 8^{+}$Treg populations were increased in the peripheral blood of patients with LP. PBMCs obtained from patients with $L P(n=18$, closed circles) and $H C(n=22$, open circles) were assessed by flow cytometry for the presence of (a) $\mathrm{CD}^{+}$Tregs $\left(\mathrm{CD}^{+}{ }^{+} \mathrm{CD} 4^{+} \mathrm{CD} 25^{+}\right.$Foxp $\left.3^{+} \mathrm{CD} 127^{\text {low/- }}\right)$ and $\mathrm{CD} 8^{+}$Tregs $\left(\mathrm{CD} 3^{+} \mathrm{CD} 8^{+} \mathrm{CD} 25^{+}\right.$Foxp $\left.3^{+} \mathrm{CD} 127^{\text {low/- }}\right)$, $\mathbf{b}$ thymus-derived $\mathrm{CD} 4^{+}$ Tregs (CD4 ${ }^{+} \mathrm{CD} 45 \mathrm{RA}^{+}$Foxp3 $3^{\text {low }}$ ) and thymus-derived $\mathrm{CD} 8^{+}$Tregs $\left(\mathrm{CD} 8^{+} \mathrm{CD} 45 \mathrm{RA}{ }^{+}\right.$Foxp $\left.3^{\text {low }}\right)$, and (c) peripherally derived $\mathrm{CD} 4^{+}$Tregs $\left(C D 4^{+}\right.$CD45RA ${ }^{-}$Foxp $\left.3^{\text {high }}\right)$ and peripherally derived CD8 ${ }^{+}$Tregs $\left(C D 8^{+}{ }^{C D} 45 R A^{-}\right.$FoxP3 $\left.3^{\text {high }}\right)$. The results are shown as the mean $\pm S E M .{ }^{*} \mathrm{P}<0.05$, ${ }^{* *} \mathrm{P}<0.01$ when compared with the $\mathrm{HC}$ group

TLR9 activation, but it was not altered by SEB stimulation (Fig. 3a). Moreover, the patients with LP had a higher frequency of unstimulated $\mathrm{CD} 4^{+} \mathrm{IL}-10^{+} \mathrm{T}$ cells, whereas this population decreased following TLR4 or SEB stimulation.

Unstimulated $\mathrm{CD}^{+} \mathrm{T}$ cells exhibited increased production of proinflammatory cytokines, such as IFN- $\gamma$ and IL-22 (Additional file 4: Figure S4). After stimulation with CL097/TLR7-8 or SEB, the LP group displayed a high frequency of IL-22+ cells (Additional file 4: Figure S4b). Upon TLR9 stimulation, the frequency of $\mathrm{CD}^{+} \mathrm{T}$ cells secreting TNF or IFN- $\gamma$ (Additional file 4: Figure S4c) decreased in the LP group.

We also evaluated the ratios between Th17 cells and Tregs and Th1 cells and Tregs using baseline data (Additional file 5: Figure S5). These ratios were similar between the LP and HC groups.

\section{Patients with LP exhibit increased frequencies of Th22 and Tc22 cells}

To evaluate the frequencies of Th22 and Tc22 cells in peripheral blood, we analysed production of the cytokines IL-17, IFN- $\gamma$ and IL-22 in T cells via flow cytometry. Th22 and Tc22 cells are $\mathrm{IL}-17^{-} \mathrm{IFN}-\gamma^{-} \mathrm{IL} 22^{+}$, and the gating strategy used to identify these cells is shown in Fig. 4a.
Under no-stimulation conditions, the LP group exhibited increased frequencies of Th22 and Tc22 cells compared to the HC group; this trend remained for Th22 cells following stimulation with SEB (Fig. 4b).

\section{TLR activation induces the production of polyfunctional T cells in patients with LP}

Next, we evaluated whether stimulation of PBMCs with TLRs could induce the production of polyfunctional $\mathrm{T}$ cells in patients with LP. To accomplish this, we assessed levels of the cytokines IL-17, IL-10, IFN- $\gamma$, TNF and IL-22 in T cells via flow cytometry using a Boolean gating strategy, which is described in Additional file 3: Figure S3c. As shown in Fig. 5, the patients with LP had fewer $\mathrm{CD} 4^{+} \mathrm{T}$ cells that simultaneously secreted the 5 evaluated cytokines following treatment with CL097 and CpG. However, TLR4 or TLR7/8 and TLR9 activation induced the production of some of these cytokines in T cells from patients with LP, although these cells did not appear to produce IL-10. Moreover, in the patients with LP, we observed an increased frequency of $\mathrm{CD}^{+}{ }^{+} \mathrm{T}$ cells simultaneously secreting 3 of the evaluated cytokines compared to the HC following treatment with CL097 or CpG (pie chart, yellow slice). Notably, the most prominent 

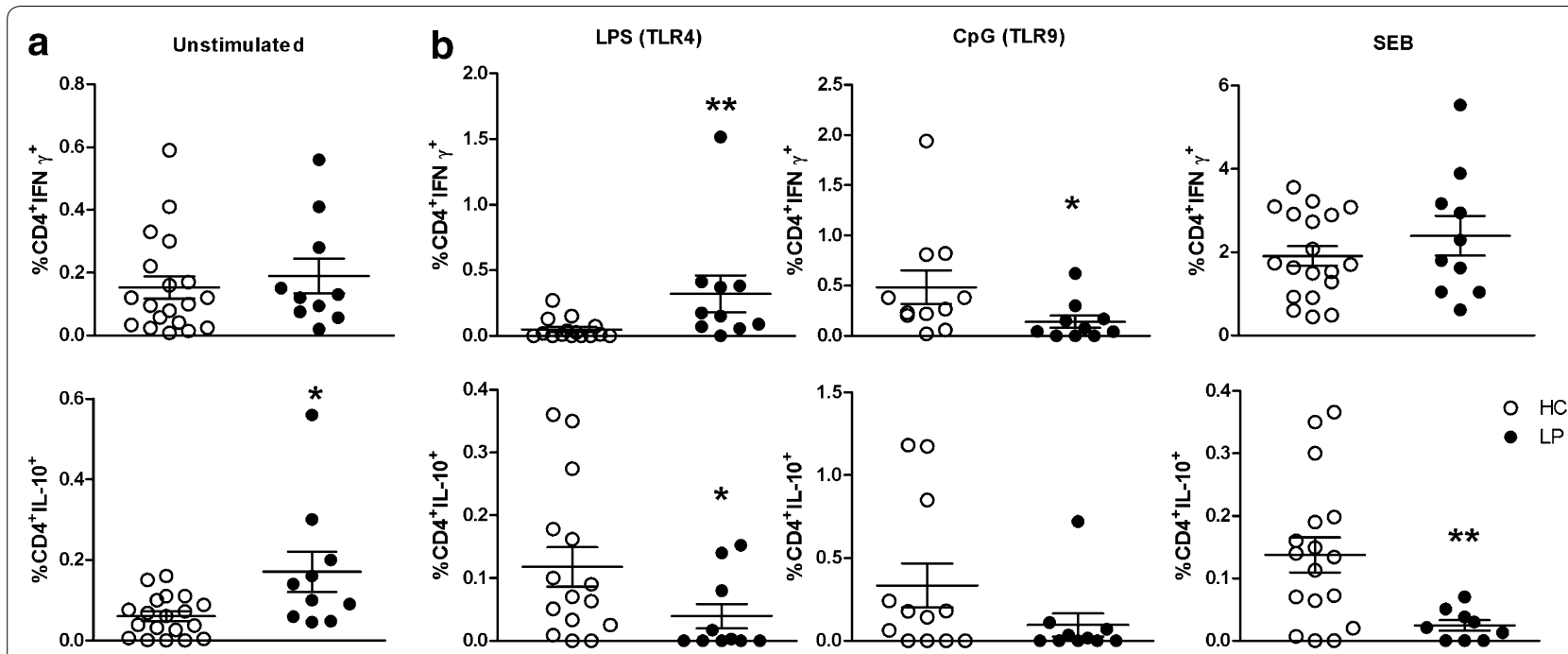

Fig. 3 Altered cytokine secretion by $C D 4^{+} T$ cells induced by TLR activation in patients with LP. PBMCs from patients with LP ( $n=13$, closed circles) and HCs ( $n=19$, open circles) were left unstimulated (a) or were stimulated with the TLR agonists LPS/TLR4, CpG/TLR9 and SEB for 16 h (b) and then assessed by flow cytometry for IFN- $\gamma$ and IL-10 secretion. The frequencies of stimulated CD4 ${ }^{+} \mathrm{T}$ cell populations were subtracted from those of unstimulated populations. The results are shown as the mean $\pm \mathrm{SEM}$. ${ }^{*} \mathrm{P}<0.05,{ }^{*} \mathrm{P}<0.01$ when compared with the HC group

combinations of 3 cytokines in this context included IL-22, IL-17, IFN- $\gamma$, or TNF, but not IL-10.

The production of polyfunctional $\mathrm{CD} 8^{+} \mathrm{T}$ cells was high in the LP group under no-stimulation conditions (Fig. 6). Following stimulation with SEB or CL097, the frequencies of $\mathrm{CD} 8^{+} \mathrm{T}$ cells that simultaneously secreted 2 , 3, or 4 of the above-referenced cytokines increased in the samples collected from the patients with LP. Although no differences were noted between the groups when the cytokines were combined, a different response was observed upon activation with CL097 (pie chart, Fig. 6).

\section{Discussion}

In this report, we identified systemic immunologic alterations that occur in patients with LP, including altered innate immune responses caused by $\mathrm{mDCs}$ secreting TNF and altered effector T cell responses [3]. Moreover, our ex vivo evaluation revealed the presence of polyfunctional $\mathrm{CD}^{+} \mathrm{T}$ cells secreting IL-22, IL-17, IFN- $\gamma$ and/ or IL-10 in parallel with increased numbers of Th22 and Tc22 cells and $\mathrm{CD} 8^{+}$and $\mathrm{CD} 4^{+}$Foxp $3^{+}$Tregs.

Previously, when evaluating PBMCs isolated from patients with LP, we observed an increase in TNF secretion following TLR4 or TLR7/TLR8 activation and a decrease in TNF following TLR7 activation. A G/A polymorphism found at position 308 in the gene encoding TNF is a risk factor for LP, regardless of the presence of HCV infection [21]. Additionally, TNF- $\alpha$ levels are increased in the saliva of individuals with OLP and in the sera of individuals with cutaneous LP, although the function of this cytokine in the context of LP is controversial [3]. Treatment to produce a TNF blockade can lead to the formation of lichenoid reactions in the skin and oral mucosa; as such, further studies are required to better understand the role of this cytokine in LP pathogenesis.

Given the importance of TNF in skin diseases, we evaluated the role of TNF- $\alpha$ in $\mathrm{mDC}$ responses to TLR activation using the compound CL097, which binds to both TLR7 and TLR8 (mDCs do not express TLR9). The activation of TLR4 and TLR7/8 induced an increase in TNF responsiveness by $\mathrm{mDCs}$ in the LP group. Although differences were not found in the co-stimulatory molecules CD80 and CD86 (data not shown), the high responsiveness of the mDCs to TLR activation could impact $T$ cell responses in patients with LP. To evaluate $\mathrm{pDC}$ responses, we used TLR7 and TLR9 agonists because these receptors are selectively expressed by human pDCs [22, 23]. Although these cells are abundant in LP lesions and scarce in blood, we found no differences in the peripheral blood samples collected from the HCs and patients with LP. Previously, we showed that patients with LP have increased serum levels of CXCL9 and CXCL10 [3]. These chemokines share the CXCR3 receptor, which is up-regulated in inflamed tissues as well as in pDCs and mDCs. The activation of these chemokines through this receptor may favour their sequestration in skin lesions. Moreover, we also showed that LP skin lesions exhibit an interferon type I signature that, interestingly, was related to the negative regulation of endogenous retrovirus expression 
a

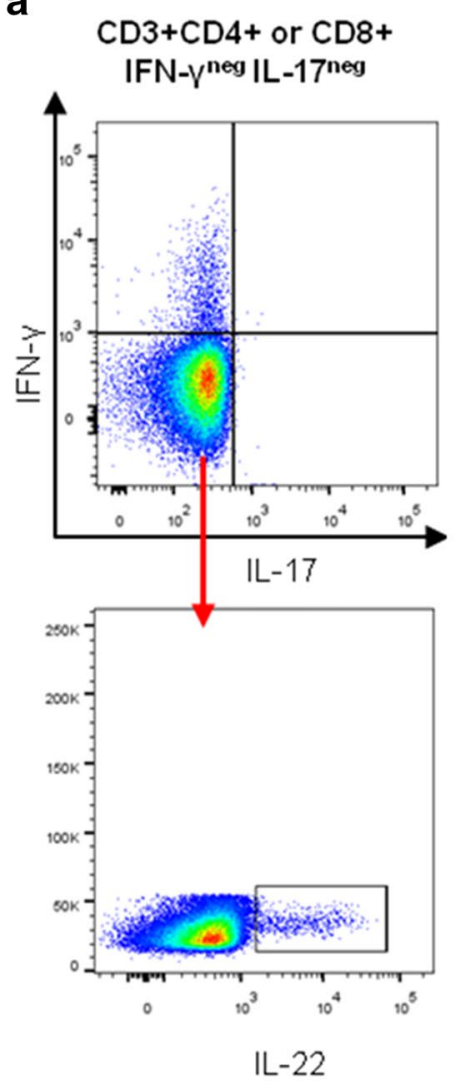

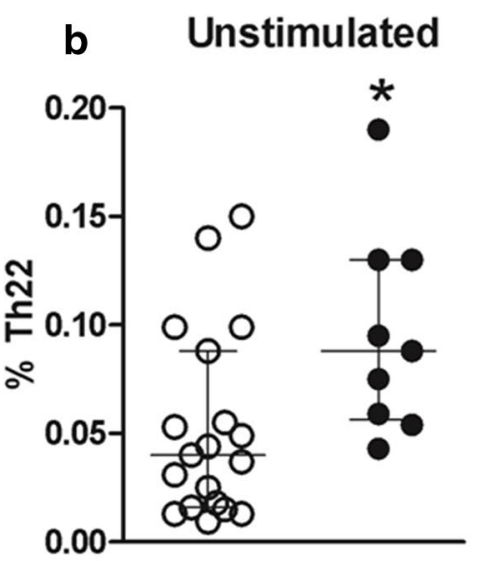
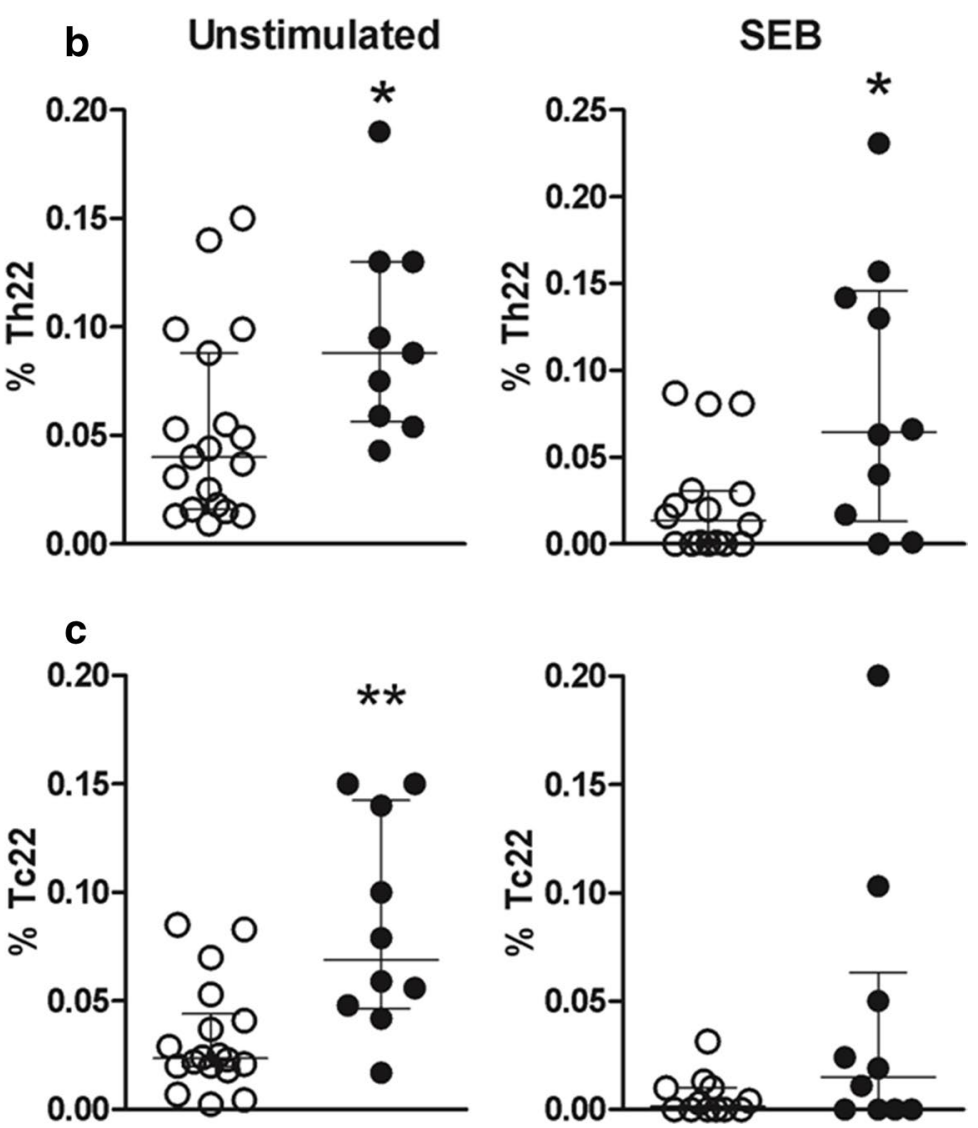

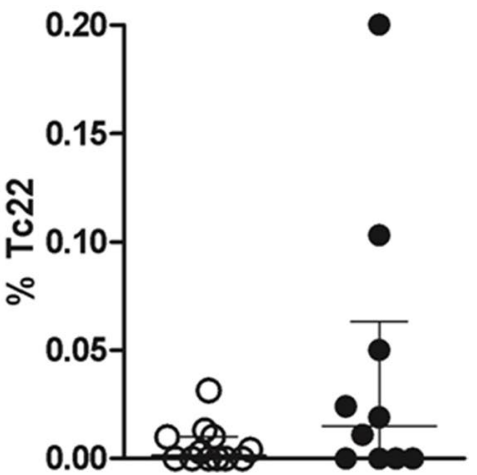

Fig. 4 Frequencies of Th22 and Tc22 cells in HCs and patients with LP. PBMCs obtained from patients with LP ( $\mathrm{n}=10$, black circles) and HCs $(\mathrm{n}=19$, white circles) were left unstimulated or were stimulated with SEB for $16 \mathrm{~h}$ and assessed by flow cytometry. A representative gating strategy for the selection of $\mathrm{CD}^{+} \mathrm{T}$ cells is shown; the same strategy was used to select $\mathrm{CD} 8^{+} \mathrm{T}$ cells $(\mathbf{a})$. Production of $\mathrm{CD} 3^{+} \mathrm{CD} 4^{+}$and $\mathrm{CD} 3^{+} \mathrm{CD} 8^{+}\left(\mathrm{IFN}-\mathrm{\gamma}^{-} \mathrm{IL}-17^{-}\right) \mathrm{T}$ cells at basal levels $(\mathbf{b})$ and following stimulation with SEB (subtracted from baseline levels) (c). The results are shown as the mean \pm SEM. ${ }^{*} \mathrm{P}<0.05$, ${ }^{*} \mathrm{P}<0.01$ when compared with the HC group

[4] and to pDC infiltration into skin lesions, a characteristic of LP [24]. These cells probably migrate to skin or to secondary lymphoid organs, where they induce adaptive immune responses such as the induction of Tregs.

The balance between regulatory and effector $\mathrm{T}$ cells was analysed, and increased percentages of $\mathrm{CD} 4^{+}$and $\mathrm{CD} 8^{+}$ Tregs were detected in the peripheral blood of patients with LP. These peripherally derived Tregs are generated outside of the thymus from $\mathrm{CD} 4{ }^{+} \mathrm{CD} 25^{-} \mathrm{T}$ cell precursors under specific stimulation conditions [25]. Moreover, unlike $\mathrm{CD} 4^{+} \mathrm{Foxp}^{+}{ }^{+}$Tregs, which are generated in the thymus, suppressive $\mathrm{CD} 8^{+} \mathrm{Foxp} 3^{+}$Tregs appear after primary antigen stimulation, suggesting that these cells are amplified by TCR stimulation, as verified in patients with inflammatory diseases such as autoimmune type 1 diabetes and multiple sclerosis $[25,26]$. Although we have not evaluated the function of these cells, the increased frequencies of $\mathrm{CD}^{+}$and $\mathrm{CD} 8^{+}$Tregs in the peripheral blood of patients with LP seem to control inflammatory immune responses in LP skin lesions [27, 28]. Studies of Tregs in the cutaneous form of LP are scarce; the majority of studies have examined OLP.

In PBMCs, the activation of TLRs is primarily thought to affect antigen-presenting cells by inducing an innate immune response that can subsequently activate the adaptive immune system. However, an increasing amount of data has demonstrated that TLRs are expressed and activated in $\mathrm{T}$ cells, thus providing evidence for a direct role of TLRs in the activation of the adaptive immune response [29]. In the current study, we found it most appropriate to evaluate the effects of TLR agonists on T cells in vitro while taking into account the involvement of DCs in the immune response to mimic the in vivo environment.

Under no-stimulation conditions, the samples from the LP group exhibited an increased frequency of $\mathrm{CD} 4^{+} \mathrm{IL}-10^{+} \mathrm{T}$ cells, which decreased upon TLR activation. In addition, TLR4 activation induced the 


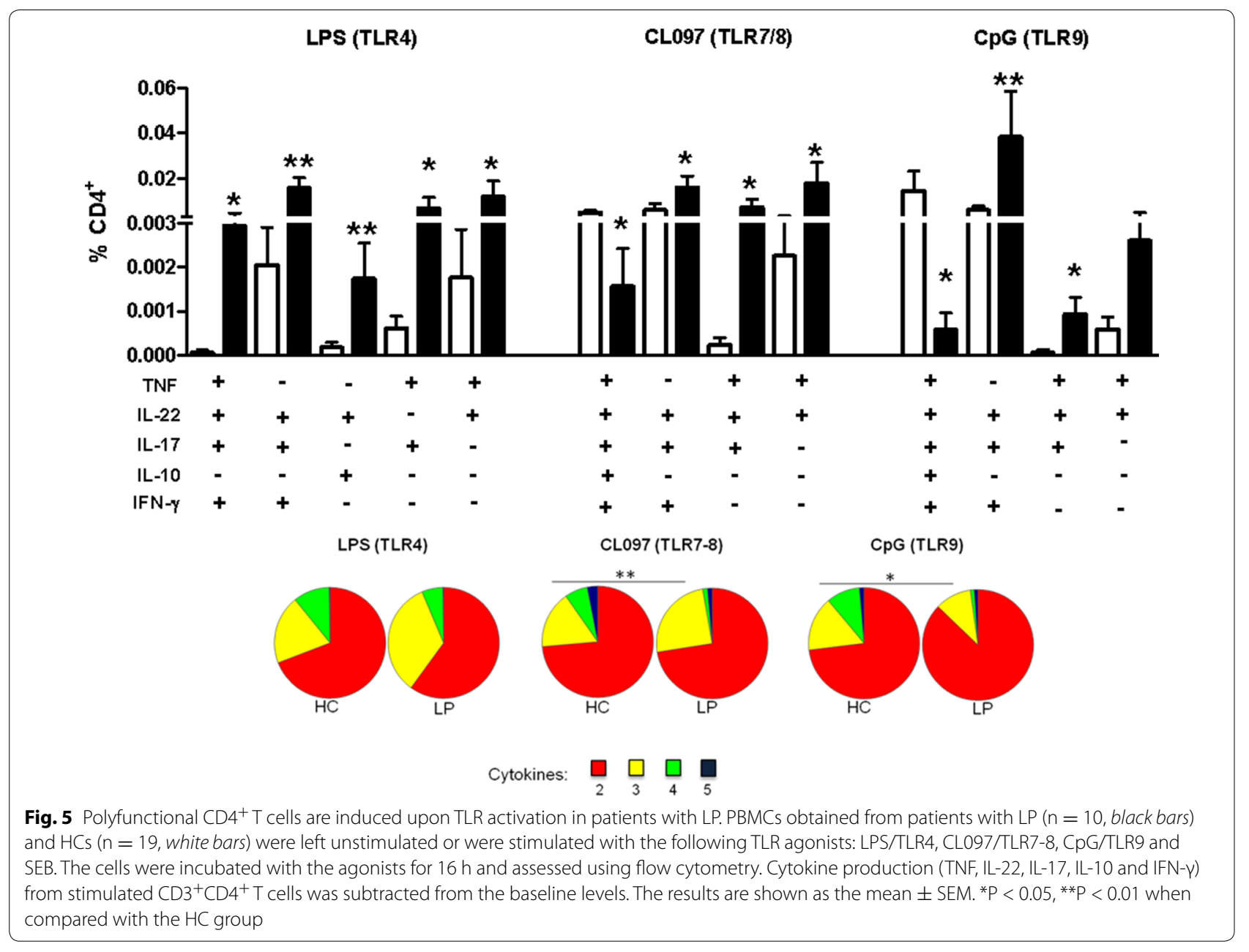

production of $\mathrm{CD} 4^{+} \mathrm{IFN}-\gamma^{+}$T cells. TLR activation also produced a proinflammatory microenvironment, which was probably modulated by $\mathrm{mDCs}$ and may lead to an inflammatory status in patients with LP due to $C D 4^{+} \mathrm{T}$ cell responses. It is notable that the TLR9 agonist used in this study down-regulated cytokine secretion from both $\mathrm{CD} 4^{+}$and $\mathrm{CD} 8^{+} \mathrm{T}$ cells in the LP group. This relationship suggests that this agonist may be an interesting adjuvant to induce tolerance and attenuate inflammatory responses in individuals with LP.

Notably, $\mathrm{CD}^{+} \mathrm{T}$ cell activation through TLR7/8 or SEB led to an increased frequency of monofunctional $\mathrm{IL}-22^{+} \mathrm{T}$ cells. Moreover, increased frequencies of Tc22 and Th2 22 cells $\left(\mathrm{IFN}-\gamma^{-}\right.$and $\mathrm{IL}-17 \mathrm{a}^{-}$) were detected in the patients with LP. These increases could result from the migration of IL-22-secreting T cells to sites of skin/ mucosal inflammation. Recent evidence indicates that IL-22 is an important cytokine for the protection and tissue remodelling of the skin, whereas Tc22 cells have been implicated in the pathogeneses of psoriasis and atopic dermatitis [30,31]. Although the frequencies of the above cell populations were increased in the LP group, the roles of IL-22 and Th22/Tc22 cells in LP are currently not well established and require further study.

Polyfunctional $\mathrm{T}$ cells can produce multiple cytokines simultaneously, providing a more effective immune response to a pathogen than cells that produce only a single cytokine [17]. In the LP group, we observed that TLR activation in PBMCs induced the production of polyfunctional T cells, mainly through the activation of the TLR7/ TLR8 pathway. Although there were fewer $\mathrm{CD} 4^{+} \mathrm{T}$ cells simultaneously secreting 5 cytokines in the LP group, there was an increased frequency of $\mathrm{CD} 4^{+} \mathrm{T}$ cells simultaneously secreting combinations of 2 or 3 cytokines. Notably, the absence of the cytokine IL-10 seemed to increase polyfunctional $\mathrm{CD} 44^{+} \mathrm{T}$ cell frequency. Multifunctional, Th1-skewed cytokine responses (identified by the simultaneous secretion of IFN- $\gamma$, IL-2, and TNF$\alpha)$ have been described to be initiated asynchronously, although the ensuing dynamic trajectories of these responses evolve in a sequential and systematic manner. In LP, we verified that multifunctional $\mathrm{CD}^{+}{ }^{+} \mathrm{T}$ cells did 


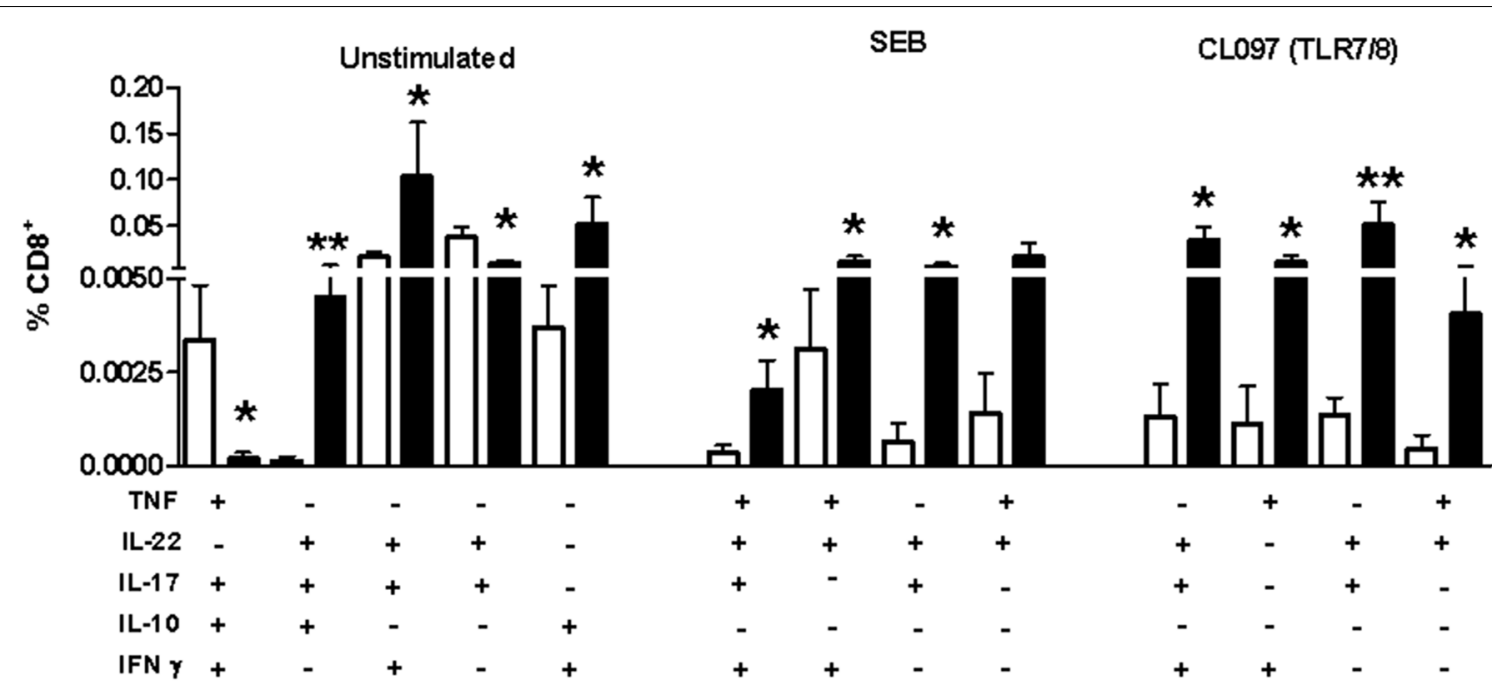

UNSTIMULATED

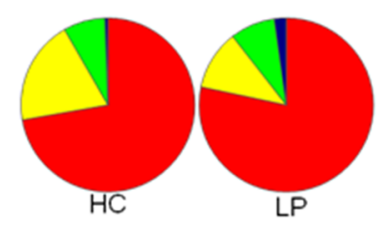

SEB
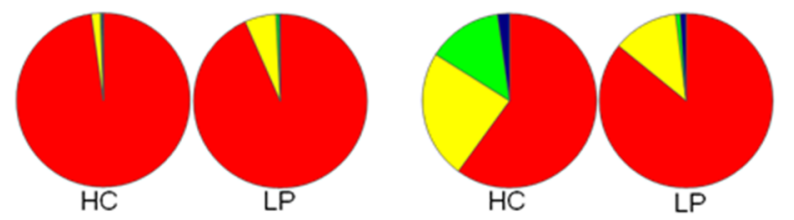

Cytokines:

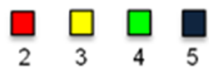

Fig. 6 Polyfunctional $\mathrm{CD}^{+}$T cells are induced upon TLR activation in patients with LP. PBMCs obtained from patients with LP ( $\mathrm{n}=10$, black bars) and HCs ( $\mathrm{n}=19$, white bars) were left unstimulated or were stimulated with the TLR agonists CL097/TLR7-8 and SEB for 16 h and assessed by flow cytometry. Cytokine production (TNF, IL-22, IL-17, IL-10 and IFN- $\gamma$ ) by stimulated CD3 ${ }^{+} \mathrm{CD} 8^{+} \mathrm{T}$ cells was subtracted from the baseline levels. The pie chart represents the capacity of T cells to secrete combinations of 5, 4, 3 or 2 cytokines. The results are shown as the mean \pm SEM. ${ }^{*} P<0.05$, ${ }^{* *} \mathrm{P}<0.01$ when compared with the HC group

not secrete IL-10 upon activation, suggesting a possible defect in the IL-10 pathway in this cell population.

Polyfunctional $\mathrm{T}$ cells (i.e., single cells producing two or more immune mediators) play a role in controlling HIV and other persistent infections [18, 32]. Although polyfunctional $\mathrm{T}$ cells represent a very low frequency of total $\mathrm{CD}^{+}{ }^{+}$and $\mathrm{CD}^{+} \mathrm{T}$ cells (in addition to monofunctional $\mathrm{T}$ cells) in HIV patients, these cells could lower viral load and have been associated with longterm suppression of AIDS progression [33]. Moreover, $\mathrm{HCV}$-specific $\mathrm{T}$ cell responses have been associated with effective control of HCV replication [34]. Whether levels of unstimulated polyfunctional $\mathrm{CD}^{+} \mathrm{T}$ cells increased in association with viral infections in patients with LP must be further explored. In our LP cohort, we observed a high prevalence of previous viral infections (e.g., cytomegalovirus, herpes simplex virus, and Epstein-Barr virus) but no cases of infection with HCV, which is the virus typically associated with LP [4]. Indeed, the aetiology of LP is still unclear, although possible causes include viral infections such as those caused by human herpes virus type 7 or $\mathrm{HCV}$, which induce multifunctional populations of $\mathrm{T}$ cells $[2,34]$.

In summary, we detected a disequilibrium between regulatory and effector functions in T cells in the peripheral blood of patients with LP. Our results indicated that TLR ligands could be used as adjuvants for the modulation of immune responses in LP.

\section{Conclusions}

In the current study, we showed that LP is associated with an altered innate immune response mediated through the responses of TNF- $\alpha^{+}$mDCs to TLR activation. Alterations in the production of $\mathrm{T}$ effector cells with increased Th22/Tc22 subpopulations and impairments in IL-10 secretion from CD4 ${ }^{+} \mathrm{T}$ cells were induced by TLR stimulation. These results suggest the presence of regulatory cells in the blood of patients with LP, indicating 
that the inflammatory response associated with LP is not restricted to the skin. Moreover, polyfunctional $\mathrm{T}$ cells provide a robust immune response may be useful as an adjuvant for the treatment of LP.

\section{Additional files}

Additional file 1: Figure S1. The gating strategy used to evaluate dendritic cells. The gating strategy used to evaluate $\mathrm{mDC}$ (CD11c) and pDC (CD123) populations in PBMCs collected from healthy individuals. The subsequent panel illustrates the population of interest producing each studied cytokine upon SEB (mDCs) and CpG (pDCs) stimulation.

Additional file 2: Figure S2. The gating strategy used to evaluate $C D 4^{+}$ Tregs. A representative gating strategy with the selection of $\mathrm{CD}_{4}^{+}$Tregs and subtypes. A similar gating strategy was used for $\mathrm{CD} 8^{+}$Treg subsets (data not shown).

Additional file 3: Figure S3. The gating strategy used to evaluate mono- and polyfunctional $\mathrm{CD} 4^{+} \mathrm{T}$ cells. A representative gating strategy used for the selection of $\mathrm{CD}^{+} \mathrm{T}$ cells (a). A similar gating strategy was used for $\mathrm{CD}^{+} \mathrm{T}$ cell subsets (b). Each subsequent panel depicts only the population of interest producing each studied cytokine after TLR or SEB stimulation. Boolean gating was used to calculate the proportions of polyfunctional T cells (c); a similar gating strategy was used for $\mathrm{CD}^{+}$ polyfunctional $T$ cell subsets.

Additional file 4: Figure S4. Altered cytokine secretion by $\mathrm{CD} 8^{+} \mathrm{T}$ cells upon TLR activation in patients with LP. PBMCs obtained from patients with $L P(n=13$, closed circles) and HCs $(n=19$, open circles) were left unstimulated (a) or were stimulated with the TLR agonists CL097/TLR78, CpG/TLR9, and SEB for $16 \mathrm{~h}$ (b) and then assessed for IFN- $\gamma$, IL-22 and TNF secretion from $\mathrm{CD}^{+} \mathrm{T}$ cells using flow cytometry. The frequencies of stimulated $\mathrm{CD}^{+} \mathrm{CD}^{+} \mathrm{T}$ cells were subtracted from the unstimulated values. The results are shown as the mean \pm SEM. ${ }^{*} p<0.05,{ }^{* *} p<0.01$ when compared with the $\mathrm{HC}$ group.

Additional file 5: Figure S5. Ratios of Th17 and Th1 cells to Tregs frequencies. PBMCs obtained from patients with $L P(n=6)$ and $\operatorname{HCs}(n=13)$ were left unstimulated. The results are shown as the mean \pm SEM.

\section{Abbreviations}

LP: lichen planus; DC: dendritic cells; TLR: toll-like receptors; pDC: plasmacytoid dendritic cells; mDC: myeloid dendritic cells; IFN-a: interferon alpha; TNF-a: tumour necrosis factor alpha; Tregs: T regulatory cells; IL: interleukin; TNF: tumour necrosis factor; PBMCs: peripheral blood mononuclear cells; tTreg: thymic T regulatory cells; pTreg: peripherally induced T regulatory cells; OLP: oral lichen planus; PMA: phorbol myristate acetate; Th: T helper; LPS: lipopolysaccharide; SEB: enterotoxin B from Staphylococcus aureus; HCV: hepatitis C virus; TCR: T cell receptor; AIDS: acquired immunodeficiency syndrome.

\section{Authors' contributions}

RD performed the experiments, analysed the data and drafted the manuscript. GCC helped conduct the experiments and evaluate the patients. VA selected all patients and participated in the coordination of the study. AJSD contributed materials and analytical tools. MNS participated in the design of the study and revised the manuscript. All authors have read and approved the final manuscript.

\section{Author details}

${ }^{1}$ Laboratory of Dermatology and Immunodeficiencies, LIM-56, Department of Dermatology, Medical School, University of São Paulo, Institut of Tropical Medicine of São Paulo, Av. Dr. Enéas de Carvalho Aguiar, 500, 3rd floor 24, São Paulo 05403-000, Brazil. ${ }^{2}$ Dermatological Outpatient Clinic, Hospital das Clínicas, Medical School of the University of São Paulo, São Paulo, Brazil.

\section{Acknowledgements}

We are grateful to all the individuals who participated in the study.

\section{Availability of data and materials}

The datasets supporting the conclusions of this article are included in the main manuscript.

\section{Competing interests}

The authors declare that they have no competing interests.

\section{Ethics approval and consent to participate}

The study was approved by the Ethics Committee for Research Project Analysis-(CAPPesq) Hospital of Clinical and Medical School of University of São Paulo (Approval Statement: CAPPesq number 0709/11). All the subjects provided written informed consent under the approval of the São Paulo University Institutional Use Committee.

\section{Funding}

This work was supported by Fundação de Amparo a Pesquisa do Estado de São Paulo (2011/20740-3) and the Laboratory of Dermatology and Immunodeficiencies, LIM-56, Department of Dermatology, Medical School, University of São Paulo, Brazil.

Received: 2 February 2016 Accepted: 2 June 2016

Published online: 10 June 2016

\section{References}

1. Lodi G, Giuliani M, Majorana A, Sardella A, Bez C, Demarosi F, et al. Lichen planus and hepatitis $C$ virus: a multicentre study of patients with oral lesions and a systematic review. Br J Dermatol. 2004;151(6):1172-81.

2. De Vries HJ, van Marle J, Teunissen MB, Picavet D, Zorgdrager F, Bos $J \mathrm{D}$, et al. Lichen planus is associated with human herpesvirus type 7 replication and infiltration of plasmacytoid dendritic cells. Br J Dermatol. 2006;154(2):361-4.

3. Domingues R, de Carvalho GC, da Silva Oliveira LM, Futata Taniguchi E, Zimbres JM, Aoki V, et al. The dysfunctional innate immune response triggered by toll-like receptor activation is restored by TLR7/TLR8 and TLR9 ligands in cutaneous lichen planus. Br J Dermatol. 2015;172(1):48-55.

4. De Sousa Nogueira MA, Biancardi Gavioli CF, Pereira NZ, de Carvalho GC, Domingues $\mathrm{R}$, Aoki V, et al. Human endogenous retrovirus expression is inversely related with the up-regulation of interferon-inducible genes in the skin of patients with lichen planus. Arch Dermatol Res. 2014;259:307.

5. Scheler M, Wenzel J, Tüting T, Takikawa O, Bieber T, von Bubnoff D. Indoleamine 2,3-dioxygenase (IDO): the antagonist of type I interferondriven skin inflammation? Am J Pathol. 2007;171(6):1936-43.

6. Sakaguchi S, Miyara M, Costantino CM, Hafler DA. FOXP3 + regulatory T cells in the human immune system. Nat Rev Immunol. 2010;10(7):490-500.

7. Sakaguchi S, Vignali DA, Rudensky AY, Niec RE, Waldmann H. The plasticity and stability of regulatory T cells. Nat Rev Immunol. 2013;13(6):461-7.

8. Abbas AK, Benoist C, Bluestone JA, Campbell DJ, Ghosh S, Hori S, et al. Regulatory $T$ cells: recommendations to simplify the nomenclature. Nat Immunol. 2013:14(4):307-8.

9. Burocchi A, Colombo MP, Piconese S. Convergences and divergences of thymus- and peripherally derived regulatory $T$ cells in cancer. Front Immunol. 2013:4:247.

10. Lei L, Zhan L, Tan W, Chen S, Li Y, Reynolds M. Foxp3 gene expression in oral lichen planus: a clinicopathological study. Mol Med Rep. 2014;9(3):928-34.

11. Xie S, Ding L, Xiong Z, Zhu S. Implications of Th1 and Th17 cells in pathogenesis of oral lichen planus. J Huazhong Univ Sci Technolog Med Sci. 2012;32(3):451-7.

12. Sugerman PB, Savage NW. Oral lichen planus: causes, diagnosis and management. Aust Dent J. 2002;47(4):290-7.

13. Viguier M, Bachelez H, Poirier B, Kagan J, Battistella M, Aubin F, et al. Peripheral and local human papillomavirus 16-specific CD8 ${ }^{+}$T-cell expansions characterize erosive oral lichen planus. J Invest Dermatol. 2015;135(2):418-24

14. Tokura Y, Mori T, Hino R. Psoriasis and other Th17-mediated skin diseases. J UOEH. 2010;32(4):317-28. 
15. Henseler T, Christophers E. Disease concomitance in psoriasis. J Am Acad Dermatol. 1995;32(6):982-6.

16. Miyagaki T, Sugaya M. Recent advances in atopic dermatitis and psoriasis: genetic background, barrier function, and therapeutic targets. J Dermatol Sci. 2015;78(2):89-94.

17. Han Q, Bagheri N, Bradshaw EM, Hafler DA, Lauffenburger DA, Love JC. Polyfunctional responses by human $T$ cells result from sequential release of cytokines. Proc Natl Acad Sci USA. 2012;109(5):1607-12.

18. Perreau M, Levy Y, Pantaleo G. Immune response to HIV. Curr Opin HIV AIDS. 2013;8(4):333-40.

19. Prezzemolo T, Guggino G, La Manna MP, Di Liberto D, Dieli F, Caccamo N. Functional signatures of human CD4 and CD8 T cell responses to Mycobacterium tuberculosis. Front Immunol. 2014;5:180.

20. Chong SZ, Wong KL, Lin G, Yang CM, Wong SC, Angeli V, et al. Human $\mathrm{CD}^{+} \mathrm{T}$ cells drive Th1 responses through the differentiation of TNF/iNOSproducing dendritic cells. Eur J Immunol. 2011;41(6):1639-51.

21. Jin $X$, Wang J, Zhu L, Wang L, Dan H, Zeng $X$, et al. Association between -308 G/A polymorphism in TNF-a gene and lichen planus: a meta-analysis. J Dermatol Sci. 2012;68(3):127-34.

22. Hémont C, Neel A, Heslan M, Braudeau C, Josien R. Human blood mDC subsets exhibit distinct TLR repertoire and responsiveness. J Leukoc Biol. 2013;93(4):599-609.

23. Jarrossay D, Napolitani G, Colonna M, Sallusto F, Lanzavecchia A. Specialization and complementarity in microbial molecule recognition by human myeloid and plasmacytoid dendritic cells. Eur J Immunol. 2001;31(11):3388-93.

24. Hussein MR. Evaluation of angiogenesis in normal and lichen planus skin by CD34 protein immunohistochemistry: preliminary findings. Cell Biol Int. 2007;31(10):1292-5.
25. Goldstein JD, Pérol L, Zaragoza B, Baeyens A, Marodon G, Piaggio E. Role of cytokines in thymus- versus peripherally derived-regulatory T cell differentiation and function. Front Immunol. 2013;4:155.

26. Mahic M, Henjum K, Yaqub S, Bjørnbeth BA, Torgersen KM, Taskén K, et al. Generation of highly suppressive adaptive CD8(+)CD25(+)FOXP3(+) regulatory $T$ cells by continuous antigen stimulation. Eur J Immunol. 2008;38(3):640-6.

27. Shen Z, Gao X, Ma L, Zhou Z, Shen X, Liu W. Expression of Foxp3 and interleukin-17 in lichen planus lesions with emphasis on difference in oral and cutaneous variants. Arch Dermatol Res. 2014;306(5):441-6.

28. Zhu Y, Li J, Bai Y, Wang X, Duan N, Jiang H, et al. Hydroxychloroquine decreases the upregulated frequencies of Tregs in patients with oral lichen planus. Clin Oral Investig. 2014;18(8):1903-11.

29. Akira S. TLR signaling. Curr Top Microbiol Immunol. 2006;311:1-16.

30. Duhen T, Geiger R, Jarrossay D, Lanzavecchia A, Sallusto F. Production of interleukin 22 but not interleukin 17 by a subset of human skin-homing memory T cells. Nat Immunol. 2009;10(8):857-63.

31. Luan L, Ding Y, Han S, Zhang Z, Liu X. An increased proportion of circulating Th22 and Tc22 cells in psoriasis. Cell Immunol. 2014;290(2):196-200.

32. Betts MR, Nason MC, West SM, De Rosa SC, Migueles SA, Abraham J, et al. HIV nonprogressors preferentially maintain highly functional HIV-specific CD8 ${ }^{+}$T cells. Blood. 2006;107(12):4781-9.

33. Graw F, Regoes RR. Predicting the impact of $C D 8^{+} \mathrm{T}$ cell polyfunctionality on HIV disease progression. J Virol. 2014;88(17):10134-45.

34. Ciuffreda D, Comte D, Cavassini M, Giostra E, Bühler L, Perruchoud M, et al Polyfunctional HCV-specific T-cell responses are associated with effective control of HCV replication. Eur J Immunol. 2008;38(10):2665-77.

\section{Submit your next manuscript to BioMed Central and we will help you at every step:}

- We accept pre-submission inquiries

- Our selector tool helps you to find the most relevant journal

- We provide round the clock customer support

- Convenient online submission

- Thorough peer review

- Inclusion in PubMed and all major indexing services

- Maximum visibility for your research

Submit your manuscript at www.biomedcentral.com/submit
() Biomed Central 